Renau-Morata, B. R., S. G. Nebauer, E. Sales, J. Allainguillaume, P. Caligari and J. Segura (2005): Genetic diversity and structure of natural and managed populations of Cedrus atlantica (Pinaceae) assessed using random amplified polymorphic DNA. American Journal of Botany 92: 875-884.

Schneider, S., D. Roessli and L. Excoffier (2000): Arlequin ver. 2.000: A software for population genetics data analysis, Genetics and Biometry Laboratory, University of Geneva, Switzerland.

TANG, S. Q., W. J. DAI, M. S. LI, Y. Zhang, Y. P. GENG, L. WANG and Y. ZHONG (2007): Genetic diversity of relictural and endangered plant Abies ziyuanensis (Pinaceae) revealed by AFLP and SSR markers. Genetica in press.

Tsumura, Y., K. OHBA and S. H. Strauss (1996): Diversity and inheritance of inter-simple sequence repeat polymorphisms in Douglas-fir (Pseudotsuga menziesii) and sugi (Cryptomeria japonica). Theoretical and Applied Genetics 92:

WALther, H. (1999): Die Tertiaerflora von Kleinsaubernitz bei Bautzen. Palaeontographica Abteilung B 249: 63-174.
WANG, X. P. and Y. K. LIU (1994): Theory and practice of biodiversity. China Environmental Science Press, Beijing.

WolfE, A. D. and A. LiSTON (1998): Contributions of PCRbased methods to plant systematics and evolutionary biology, pp. 43-86. In: Plant molecular systematics II, edited by D. E. Soltis, P. S. Soltis and J. J. Doyle, Kluwer, Boston.

WU, Z. Y. (1980): The vegetation of China. Science Press, Beijing.

YANG, Q. J., H. XU, Z. G. YAN, Y. LIU, K. G. ZhaO and L. Q. CHEN (2006): Natural resources and conservation of Taiwania cryptomerioides in Hubei Province. Guihaia 26: 551-556.

YANG, W. M. and S. Y. JIANG (1999): Investigation of relict Taiwania flousiana in Fujian Province. Forest By-Product and Speciality in China 4: 55-57.

YeH, F. C., R. C. YANG and T. Boyle (1999): POPGENE. Microsoft windows Based Freeware for Population Genetic Analysis Release 1.31, University of Alberta, Edmonton.

ZietKiewicz, E., A. RAFALski and D. LABUdA (1994): Genome fingerprinting by simple sequence repeat (SSR)-anchored polymerase chain reaction amplification. Genomics 20: 176-183.

\title{
Genetic Variation Within Two Sympatric Spotted Gum Eucalypts Exceeds Between Taxa Variation
}

\author{
By J. W. OChIENG ${ }^{1), 4), *)}$, M. ShePherD ${ }^{1)}$, P. R. BAVERStock ${ }^{1)}$, G. NiKLES ${ }^{2)}$, D. J. LeE ${ }^{3)}$ and R. J. HenRY ${ }^{1)}$
}

(Received 29 $9^{\text {th }}$ April 2007)

\begin{abstract}
Population substructure and hybridization, among other factors, have the potential to cause erroneous associations in linkage disequilibrium $(L D)$ mapping. Two closely related spotted gum eucalypts, Corymbia variegata and C. henryi (Myrtaceae) occur in sympatry in the east coast of Australia and potentially interbreed. They are morphologically similar but are distinguished as separate species based on capsule and foliage size. To determine whether they hybridize in nature and its

1) Centre for Plant Conservation Genetics, Southern Cross University, P. O. Box 157 Lismore, NSW, 2480, Australia.

2) Department of Primary Industries and Fisheries, 80 Meiers Road, Indooroopilly, Queensland, Australia.

${ }^{3}$ ) Department of Primary Industries and Fisheries, LB 16 Fraser Road, Gympie 4570, Queensland, Australia.

4) Permanent address: Faculties of Agriculture \& veterinary Medicine, University of Nairobi, P.O. Box 30197 Nairobi, Kenya. E-mail: jochieng@uonbi.ac.ke

*) Communicating author: Joel W. OChieng. Centre for Plant Conservation Genetics, Southern Cross University, P.O. Box 57 Lismore, NSW 2480 Australia. Tel: +61 26620 3961; Fax: +6126622 2080. E-mail: jochieng@uonbi.ac.ke
\end{abstract}

implications for $L D$ mapping, we investigated the level of molecular divergence between the two species at two sympatric locations separated by 300 kilometres. Very few individuals of intermediate morphology were identified, despite the two species occurring only metres apart. Analysis of genetic structure using 12 microsatellite loci showed that genetic differentiation between populations of the same species at different locations $\left(F_{\mathrm{ST}}=0.07\right.$ for both species; $\left.p=0.0001\right)$ was significantly higher than that observed between species at each location (mean $F_{\mathrm{ST}}=0.02$ and 0.04 for Cherry tree and Bunyaville respectively; $p=0.0001$; all Mann-Whitney $U$-test $p \leq 0.01)$. No species-specific alleles or significant allele frequency differences were detected within a site, suggesting recurr\#ent local gene flow between the two species. The lack of significant allele frequency differences implies no population stratification along taxonomic lines. This suggested that there is little concern for cryptic hybridization when sampling from sites of sympatry for $L D$ mapping.

Key words: panmixia, hybridization, gene flow, association mapping, population structure, admixture, reproductive isolation, linkage disequilibrium. 


\section{Introduction}

Association mapping, also known as linkage disequilibrium $(L D)$ mapping, is a method for identifying chromosomal regions associated with quantitative traits (PRITChARD and RosenberG, 1999). The most common problems with $L D$ in association studies are spurious associations, or false positives, caused by population structure or admixture (PRITCHARD and PRZEWORSKI, 2001). Population structure is the presence of mating subgroups within the population, known as demes, usually resulting in differences in alleles and hence allele frequencies among these groups (HARTL, 2000). Other causes include founder effects and population bottlenecks, population inbreeding (HARTL, 2000), and natural selection (HIRSCHHORN et al., 2002). Spurious associations resulting from hybridization or admixture can occur when the sampling is done without regard to racial background and the resulting samples contain different frequencies of each race (PRITCHARD and ROSENBERG, 1999), and whenever the frequency of the trait differs among the parent populations (PRITCHARD and ROSENBERG, 1999). In a situation were two closely related species occur in sympatry and potentially interbreed, their evolutionary histories and the extent of hybridisation will have implications on how $L D$ mapping is approached.

Two closely related spotted gum eucalypts: Corymbia variegata and C. henryi (Myrtaceae) occur in sympatry in the east coast of Australia. Both species have a potential as sources of fibre from both plantations and native forests and are subject to tree improvement in subtropical Australia (DICKINSON et al., 2004; LEE et al., 2004; LeE, 2007; SMith, Henson and Boyton, unpublished). Although generally similar, the two taxa are regarded as separate species based on divergence at quantitative traits, such as fruit (capsule) and foliage morphology (Hill and JoHnson, 1995).

Initial attempts to clarify the relationships amongst the spotted gums by molecular approaches (McDoNALD et al., 2000; KING, 2004) provided conflicting results on the affinity of these two species. More recently, however, a study on a couple of representatives from each species from a range of sites across their distribution range using microsatellite markers, showed that genetic differentiation between populations of the same species exceeded that observed between species at each site, suggesting a very close relationship between these two species (OCHIENG et al., 2006). Extension of this study to include all four recognised spotted gum taxa, confirmed little differentiation between the two species, showing a stronger affinity between all three northern taxa, $C$. citriodora; C. variegata and $C$. henryi, compared to their southern counterpart, C. maculata (SHEPHERD et al., unpublished). The two species occur sympatrically over a large portion of their ranges, have overlapping flowering times and share a common set of insect and vertebrate pollinators (HILL and JoHNSON, 1995; SOUTHERTON et al., 2004). Furthermore, we have observed synchronous flowering of the two taxa in native forests, and identified a few individuals of intermediate capsule and foliage morphology at sympatric locations, all suggesting natural hybridisation is likely. Controlled crossing and establishment of hybrids in field trials has confirmed the interfertility of the two species (LEE, unpublished), however, it remains unknown if they hybridized in nature, and the extent to which extrinsic and intrinsic reproductive barriers isolate the two species.

Three major hypotheses, each with a unique effect on $L D$ mapping, might explain the maintenance in sympatry of two phenotypically distinct species: First, the two species could represent two evolutionary lineages that evolved in allopatry and are making a secondary contact (PANOvA et al., 2006). If they hybridize and hybrids grow to adult stage and got sampled inadvertently, then hybridization can cause spurious associations in $L D$ mapping due to cryptic allelic strata in the mapping population. Second, the pair could represent a single evolutionary lineage with morphological variation attributable to a gene (or a few genes) with large effects (Genic species; Doebley and LuKens, 1998; Wu et al., 2001). This scenario is unlikely to complicate $L D$ mapping because differentiation between the two species is confined to a few genome blocks, whereas the rest of their genomes would be panmictic. Finally, they might represent evolutionary lineages that are evolving in sympatry and have developed reproductive barriers (GRAHAME et al., 2004). This also would not complicate $L D$ mapping if species are well identified. For completeness, two additional models are mentioned as they could also explain the maintenance in sympatry of two phenotypically distinct species: First, either of the species could be a hybrid with a third spotted gum species or with another Corymbia spp. (hybrid speciation). Second, it is possible that the two species are convergent morphologically, often occurring in sympatry, but are not hybridizing and are distantly related. These two hypotheses, however, can be discounted on the basis of recent phylogenetic analyses among eucalypt genera using neutrally evolving ribosomal ITS sequences (OCHIENG et al., 2007), neutral microsatellites (OCHIENG et al., in press), and phylogenetic analyses within the spotted gum based on isozymes (KING, 2004) and neutral microsatellites (OchiEnG, J.W., SHEPherd, M. and HENRY, R. J., unpublished).

In a further step to characterise the relationship between $C$. variegata and $C$. henryi and infer the degree of hybridization (if any), we expand the sample size in both species across two sites where they are sympatric, and examined the degree of differentiation between species at 12 microsatellite loci. The two sites are located approximately $300 \mathrm{~km}$ apart on either side of a distribution disjunction in both species that aligns with a major topographical feature, the Border Ranges. Hence the two sites are likely to represent more divergent populations of each species if gene flow is restricted across the disjunction. Sampling aimed to collect individuals representing both species as well as putative hybrids based on intermediate morphology. For simplicity, samples of the same species at a site will be referred to as a population. If interspecific differentiation were stronger than intersite differentiation this would tend to support the hypothesis that the two species have developed intrinsic reproductive barriers. If on the other hand, interspecies differentiation is less than intersite differ- 
ences, this would tend to support the hypothesis that the two taxa are either introgressing in a secondary contact (PANOVA et al., 2006), or are genic species (Wu et al., 2001).

\section{Methods}

\section{Sample collection}

Samples were taken from trees of both species at two sites of sympatry (Figure 1) separated by about $300 \mathrm{~km}$ : Cherry tree state forest, NSW (S 2857 56; E 15244 58) (C. henryi $\mathrm{N}=35 ;$ C. variegata $\mathrm{N}=35$ ) and Bunyaville state forest, Queensland (S 2722 19; E 15257 22) (C. henryi $\mathrm{N}=26 ;$ C. variegata $\mathrm{N}=26$ ). At both sites, bark samples were taken from paired $C$. variegata and C. henryi trees or putative hybrids growing within 50 metres, but separated from the next pair by at least 100 metres. We sampled mature trees with capsules, buds or flowers because these could more accurately be classified. Herbarium specimens (capsules, buds, flowers, foliage) were sent to the Queensland Herbarium, where field classification of samples into the two species or hybrids by the authors was confirmed. 24 Samples of C. maculata- four from each of six provenances: Kioloa State Forest (SF), Wigello SF, Bodalla SF, Nelligen SF, Mumbulla SF, all in NSW, and Mottle Range SF in Victoria, was included to root population clustering tree. All these locations are allopatric to both $C$. variegata and $C$. henryi.

\section{DNA extraction and PCR amplification}

Bark (30 mg) or leaf (10 mg; C. maculata) tissue was snap chilled in liquid nitrogen and ground using tungsten carbide beads (QIAGEN) and a RETSCH MM300 Mixer Mill. This was followed by genomic DNA extrac-

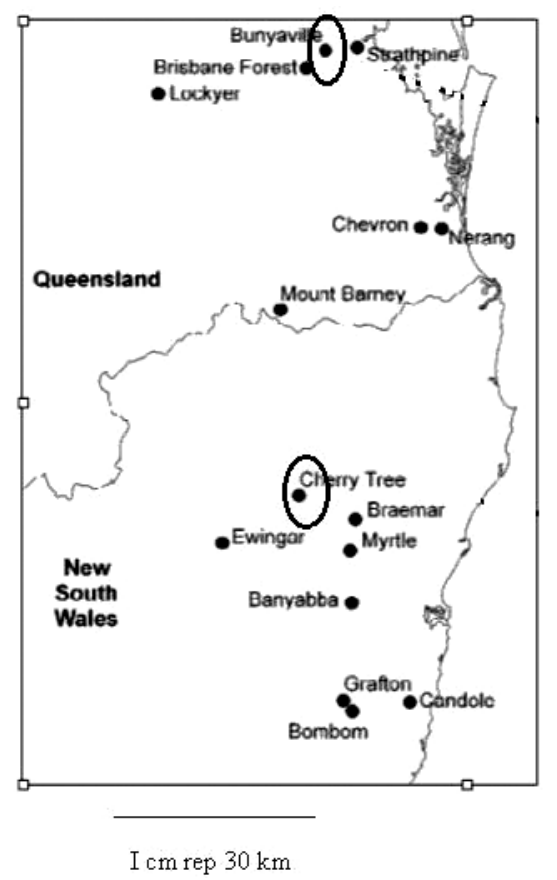

Figure 1. - Map showing the sympatric distribution of C. variegata and C. henryi spotted gums in the east coast of Australia. The two locations sampled in this study are marked in large circles. tion using a DNeasy plant kit (QIAGEN, Germany) according to the manufacturer's protocol for fresh tissue extraction and stored at $-20^{\circ} \mathrm{C}$. Twelve SSRs belonging to six (6) different linkage groups: EMCRC26, EMCRC31, EMCRC33, EMCRC39 (JoNES et al., 2001); EMCRC41, EMCRC45, EMCRC46, EMCRC51, EMCRC54, EMCRC55, EMCRC93 (SHEPHERD et al., 2006); CSIRO Eg126 (THAMARUs et al., 2002) were used in this study. For each primer pair, the forward primer was fluorescently labelled with a dye to enable fluorescent detection. Amplifications were carried out as described previously (JoNES et al., 2001). The PCR products were separated on a 3730 DNA analyser at Southern Cross Plant Genomics (SCPG), Lismore, Australia, and raw data were analysed using ABI Prism GeneMapper Software v 3.0 (Applied Biosystems).

\section{Statistical analyses}

Possible nonrandom allelic associations between pairs of loci were assessed within each population and globally using Fisher's exact test on contingency tables, implemented in GENEPOP on the web, version 3.3 (RAYMOND and Rousset, 1995). The significance level for each test was adjusted using sequential Benferroni procedure (RICE, 1989). The confidence level for the null hypothesis was set to $99 \%$. Gene diversity (NEI, 1987), inbreeding coefficient $F_{\text {IS }}$, Observed heterozygosity $\left(H_{\mathrm{O}}\right)$ and the mean number of alleles (MNA) per population was calculated using GENEPOP. Genetic variation among populations and among groups of populations within species was analysed using AMOVA (ExCOFFIER et al., 1992) as implemented in ARLEQUIN Version 2.0 (SCHNEIDER et al., 2000). Levels of population genetic differentiation $\left(F_{\mathrm{ST}}\right.$; WEIR and CocKeRHAM, 1984) was estimated in GENEPOP and their significance assessed by the loglikelihood exact G-test on genotypes (GOUDET et al., 1996). $F_{\mathrm{ST}}$ is based on the infinite allele model of mutation (IAM), in which each mutation creates a novel allele. $F_{\text {ST }}$ does not weight for mutational differences between alleles- it assumes that new alleles in a population are due to migration rather than mutation. $R_{\mathrm{ST}}$ (SLATKIN, 1995), which assumes a stepwise mutational model (SMM), is the average squared difference in size of alleles. $R_{\mathrm{ST}}$ differs from $F_{\mathrm{ST}}$ in that $R_{\mathrm{ST}}$ takes allele sizes into account, whereas $F_{\mathrm{ST}}$ only uses the identity or nonidentity of an allelic state. Since the rate of mutations and the evolution model at the SSRs used here was not known, both indices were used in estimating the levels of differentiation. Pairwise $F_{\mathrm{ST}}$ values were separated into two groups: between pairs of populations of different species, and between pairs of populations of the same species. We used the non-parametric MannWhitney $U$ test to test the null hypothesis of increased genetic differentiation between populations of the same species at different locations, versus populations of different species at one location. The average $F_{\mathrm{ST}}$ estimates were translated into the average number of migrants successfully entering a population per generation, $\mathrm{Nm}$, using the equation: $F_{\mathrm{ST}}=1 /(4 N m+1)$ (WRIGHT, 1969). Finally, CAVALLI-SForzA and EDWARDS's (1967) chord distance was used to estimate genetic distances because it models short-term divergence due to drift alone (NEI, 1987) and is thus most suitable for comparing closely 
related groups. Moreover, this distance method can quantify the degree to which all populations differ from one another simultaneously for the entire pool of data. Neighbour-joining clustering of distances was done in the NEIGHBOR program of the PHYLIP package (FELSENSTEIN, 1995). 100 bootstrap pseudoreplicates were used to estimate statistical support for population dendrogram.

\section{Results}

Individuals of intermediate morphology were infrequent

Individuals of intermediate capsule or foliage morphology were infrequent. At both sampling sites, C. variegata and $C$. henryi occurred in very close proximity; most of the time only a few metres apart, with cases of overlapping canopies. This increased the opportunity for cross-pollination even by small insects such as bees. Despite targeting these sites of potential hybridization for sampling, only two putative hybrids were found at Cherry tree, while none was observed at Bunyaville. These putative hybrids were excluded from analyses.

\section{Microsatellite marker variation was high, providing power to test for structure}

Genetic diversity across the 12 SSRs was high (average number of alleles $=22.3$; Table 1 ). Observed heterozygosity $\left(H_{\mathrm{O}}\right)$ per population, Expected heterozygosity $\left(H_{\mathrm{E}}\right)$ and mean number of alleles $(M N A)$ are given in Table 1. $H_{\mathrm{O}}$ was consistently but not significantly lower than $H_{\mathrm{E}}$ for all populations and overall. Within each population, locus-specific $F_{\text {IS }}$ values ranged from -0.05 to 0.76 . Average $F_{\text {IS }}$ across loci per population ranged from 0.187 to 0.366 and were all significantly different from zero (Table 1).

\section{AMOVA indicated that structure was low}

Only $5.56 \%$ of variation was partitioned between populations and $17.3 \%$ of variation within a population (AMOVA Table 2). Most variation $(77.1 \%$ ) resided within individuals. When populations of a taxon were combined and compared to populations of the other taxon, the percentage of variation between taxa was negative $(-1.61 \%$; Table 2).

\section{Genetic differentiation was greater within each species than between species}

No species-specific alleles were identified at any of the loci studied, however, site-specific alleles were detected in at least half of the loci studied (data not shown). Genetic differentiation between populations of the same species at different sites $\left(F_{\mathrm{ST}}=0.06\right.$ and 0.07 for $C$. variegata and $C$. henryi respectively) was greater than differentiation between species at either site $\left(F_{\mathrm{ST}}=0.02\right.$ and 0.04 for Cherry Tree and Bunyaville respectively; all comparisons were significant at $p=0.01$; Table 3 ).

\section{Amalgamating species within a site did not cause $L D$ among unlinked loci}

Three locus-pairs showed significant $L D(p \leq 0.01)$ in one population (Cherry tree C. henryi): EMCRC 26 and EMCRC 31, EMCRC31 and EMCRC45, EMCRC31 and EMCRC54 (data not shown). No $L D$ was detected in either species at Bunyaville. An $L D$ test on pooled samples of both species at Bunyaville returned no significant $L D$. However, $L D$ for combined taxa at Cherry tree

Table 1. - Allelic diversity per population measured as heterozygosity $\left(H_{O}, H_{E}\right)$, mean number of alleles $(M N A)$ and the multilocus inbreeding coefficient $\left(F_{\text {IS }}\right)$. Significance values for $F_{\text {IS }}$ are given in parentheses.

\begin{tabular}{|c|c|c|c|c|c|c|}
\hline Population & $\mathrm{N}$ & Loci & $F_{\mathrm{IS}}$ & $I_{\Gamma}$ & $I_{\circ}$ & MNA \\
\hline Bunyaville $C$. henryi & 26 & 12 & $0.366(<0.01)$ & 0.803 & 0.509 & $11.33(11.33)$ \\
\hline Bunyaville $C$ variegata & 26 & 12 & $0.256(<0.01)$ & 0.832 & 0.619 & $12.83(12.83)$ \\
\hline Cherry tree C. hentyi & 35 & 12 & $0.201(80.01)$ & 0.867 & 0.692 & $15.0](11.91)$ \\
\hline Cherry tree $C$ variegata & 35 & 12 & $0.206(<0.01)$ & 0.851 & 0.676 & $14.67(11,86)$ \\
\hline Across all populations & 122 & 12 & $0.262(<0.01)$ & 0.826 & 0.641 & $20.50(12,08)$ \\
\hline C. ntaculata & 26 & 12 & $0.187(0001)$ & 0.779 & 0.633 & $12.17(09.91)$ \\
\hline
\end{tabular}

${ }^{1}$ - C. maculata was excluded in the estimation of across population indices. Values in parentheses are those obtained by rarefaction when $N=26$.

Table 2. - Summary of analysis of molecular variance (AMOVA) over 12 microsatellite loci in sympatric spotted gums.

\begin{tabular}{lrrrrr}
\hline Source of variation & d.f. & $\begin{array}{l}\text { Sum of } \\
\text { squares }\end{array}$ & $\begin{array}{l}\text { Variance } \\
\text { Components }\end{array}$ & $\begin{array}{l}\text { Percentage of } \\
\text { variation }\end{array}$ & $\begin{array}{l}\text { P-value } \\
\text { Treating each population separately: }\end{array}$ \\
Among populations & 3 & 70.111 & 0.28978 & 5.56000 & 0.00001 \\
Among individuals within pops & 118 & 686.963 & 0.90266 & 17.33000 & 0.00001 \\
Within individuals & 122 & 490.000 & 4.01639 & 77.11000 & 0.00001 \\
Combining populations: & & & & & \\
Between species & 1 & 17.198 & -0.08366 & -1.61235 & 0.64712 \\
Between sites & 1 & 34.949 & 0.14767 & 2.81000 & 0.34409 \\
\hline
\end{tabular}

$1-P$ values are significance tests obtained after 1023 permutations.

2 - Variance component and percentage of variation explained by between-species component is a negative value. 
Table 3. - Pairwise population differentiation: $\left(F_{\mathrm{ST}}\right)$ below diagonal; $\left(R_{\mathrm{ST}}\right)$ above diagonal.

\begin{tabular}{lllll}
\hline & Bunya C. hempi & Bunya C. variegata & Cheny C. henryi & Cherry C. variegata \\
\hline Bunya C. henryi & 0 & $0.0285(0.0001)$ & $0.0788(0.0001)$ & $0.1717(0.0001)$ \\
Burya C. variegata & $0.0417(0.0001)$ & 0 & $0.0894(0.0001)$ & $0.1742(0.0001)$ \\
Cherry C. henri & $0.0702(0.0001)$ & $0.0542(0.0001)$ & 0 & $0.0321(0.0001)$ \\
Cherry C. variegata & $0.0849(0.0001)$ & $0.0670(0.0001)$ & $0.0211(0.0001)$ & 0
\end{tabular}

$F_{\mathrm{ST}}$ among all four populations across loci $=0.07 ; R_{\mathrm{ST}}=0.08 . P$-values obtained by 110 permutations, are given in parentheses.

were significant $(p \leq 0.01)$ at two locus-pairs: EMCRC31 and EMCRC45, EMCRC31 and EMCRC54. These same loci showed significant $L D$ in global tests, possibly owing to the influence of Cherry tree $C$. henryi.

\section{Genetic distances and population clustering}

A Neighbour-Joining tree, clustered using CAVALLISFORZA and EDWARD's (1967) chord distance, is shown in Figure 2. The ingroup topology supported two clades representing the two geographic locations: Cherry tree and Bunyaville, rather than the two species, C. variega$t a$ and $C$. henryi. The statistical support for this alliance was high (99\% and $82 \%)$.

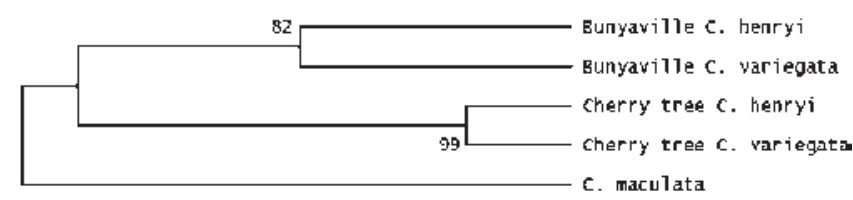

Figure 2. - A population dendrogram showing a greater genetic similarity among populations of the same geographic region than between populations of the same species. Numbers on nodes are bootstrap values.

\section{Discussion}

We have examined hybridization, a potential cause of genetic structuring in two sympatric and widespread forest trees, C. variegata and C. henryi. Microsatellite markers used in this study revealed high variation, hence ample power to detect genetic structure within and among populations. However, most variation was contained within populations, indicating an overall low structure across the entire sample set. Surprisingly, we found that genetic differentiation between populations of the same species at different sites was greater than differentiation between species at either site. No private alleles were identified for either species but some sitespecific alleles were identified. Further, pairwise $F_{\text {ST }}$ estimates showed that within species variation was two fold greater than between species. These results support a scenario where the two taxa are either genic species (WU et al., 2001) or becoming secondarily similar through local hybridization and introgression following a secondary contact (GRAHAME et al., 2004). Distinguishing between these scenarios with the present data is difficult, however, we present evidence for molecular level panmixia in two sympatric open-pollinated forest tree species with significant morphological divergence. If they hybridize and attain panmixia, how then do they remain morphologically distinct? The most parsimonious explanation is that segregation at a gene (or genes) with large effects may drive their phenotypic divergence (genic species; Wu et al., 2001). Alternatively, selection can also cause phenotypic divergence without a corresponding genomic divergence (LEXER et al., 2006). Individuals with intermediate capsule or leaf morphology (intermediate to $C$. variegata and $C$. henryi) were infrequent in nature. None was observed at Bunyaville State forest, while only two were observed at Cherry tree state forest during our sample collections. This was consistent with a scenario where the traits used to identify the species are under the control of a gene (s) with categorical effects. An example of this is the major genes affecting domestication traits in plants (DoEBLY and STEC, 1991). The alternative hypothesis is post zygotic selection against hybrids, where although hybrids grow to maturity, they have a lowered fitness. However, if hybrids were less fit, then a higher level of divergence than reported here would be expected at microsatellite loci, reflecting the development of some intrinsic reproductively barriers. Our data show that in sympatry, the two taxa are panmictic. Study of divergence at slowly evolving loci than microsatellites, may help in clarifying the evolutionary past of these species.

\section{Sympatric populations of C. variegata and C. henryi were panmictic}

This study has shown populations of $C$. variegata and $C$. henryi to comprise effectively a single panmictic unit within sampled sympatric locations. Populations in sympatry exhibited very low estimates of genetic differentiation $\left(F_{\mathrm{ST}}\right)$. Although not a robust measure of gene flow, $\mathrm{Nm}$ estimates derived from $F_{\mathrm{ST}}(\mathrm{Nm}=6 ; \mathrm{n}=35)$ indicate effective migration rates that would normally be assumed to indicate panmixia (WRIGHT, 1969). The difficulty in distinguishing interspecific gene flow from shared ancestral variation that may be contributing to the low $F_{\mathrm{ST}}$ values for sympatric species, has elicited a recent and vigorous discussion (MUIR and SCHLOTTERER, 2005; LEXER et al., 2006; MUIR and SCHLOTTERER, 2006). In a biogeographical context, gene flow is expected to result in lower levels of differentiation between neighbouring populations than among distantly located ones 
(MUIR and SCHLOTTERER, 2005). In the alternative scenario of species retaining shared ancestral alleles, however, geographical neighbours are expected to be no more differentiated than distantly located ones. In this study, genetic differentiation observed between species at each location was significantly less than that observed between populations of the same species at the two locations, suggesting that shared ancestral polymorphism is a less likely explanation than interspecific gene flow for the observed genetic affinity between these sympatric species. Clustering analysis indicated a stronger geographic than taxonomic affinity. The geometric distance used (Chord distance; CAVALLI-SFORZA and EDWARD, 1967), quantified the degree to which all populations differed from each other in the entire pool of data without the underlying biological assumptions or models. The decomposition of the four populations belonging to two species into two clades representing the two geographic locations rather than species, suggests that migration rate across the two sites is too low to counter differentiation due to drift alone. Within each locale, the rate of gene flow might be high enough to erase allele frequency differences or fixation of alternate alleles by drift. Despite this outcome, we retain the term species in our discussion because species can be separated by reproductive isolation as well as by more "ordinary" (ORR, 2001) differences in morphology that play no necessary role in blocking gene flow.

\section{Linkage disequilibrium supports the panmixia para- digm}

In this analysis, one population (Cherry tree $C$. henryi) showed significant values for pairwise $L D$ in three locus-locus combinations. Two of these disequilibria were also detected in global tests (which include the affected population) but not in other populations considered individually. Presence of population structure is expected to cause a false $L D$ even among unlinked loci (PRITCHARD and PRZEWORSKI, 2001). Amalgamating samples of both species at Bunyaville was expected to show some $L D$ if the two species comprising the pool were stratified. However, no $L D$ was detected by simulating a single population model (data not shown). This further supports a panmictic paradigm. However, $L D$ for combined taxa at Cherry tree was significant $(\mathrm{p} \leq 0.01)$ at two locus-pairs, which also showed significant $L D$ in global tests. This was expected since one of the populations at this site $(C$. henryi) showed significant $L D$ at three locus-locus combinations. The results for Cherry tree pools and the global tests are therefore likely to be influenced by this one population. A locus-pair that exhibits significant $L D$ in a single population, but no $L D$ in other populations, can be assumed to be physically unlinked. The loci whose pairwise combinations showed significant LD: EMCRC26/EMCRC31, EMCRC31/ EMCRC45, and EMCRC31/EMCRC54, all belong to different linkage groups (SHEPHERD et al., 2006) except locus EMCRC31 that was unmapped. A population showing such $L D$ among loci might be structured, hybridizing, under selection, inbred, or affected by demographic factors, such as founder effects or bottlenecks. Hardy-Weinberg tests such as the inbreeding coefficient $\left(F_{\text {IS }}\right)$ across populations, expected and observed heterozygosity, and diversity (MNA) suggested that Cherry tree $C$. henryi was less inbred compared to the other sampled populations. Thus population structure or inbreeding cannot explain the $L D$. Under strict neutrality, the expected amount of inbreeding (departure of gene frequencies within a population from metapopulation average as a result of random drift) experienced at different SSR loci should be the same because of the shared demographic history experienced at these loci (CAVALLI-SFORZA, 1966; LEWONTIN and KRAKAUER, 1973). Single locus $F_{\text {IS }}$ ranged from -0.05 to 0.275. Different $F_{\text {IS }}$ across loci might result from selection. Selection can alter the apparent degree of inbreeding at individual loci (BEAUMONT, 2005). However, these loci appear to evolve neutrality when tested on a larger set of spotted gum populations, which included those analysed here (OCHIENG, J. W., SHEPHERD, M., LEE, D. J., Raymond, C. A., Nikles, G., Baverstock, P. R. and HENRY, R. J.; unpublished). Thus the observation may indicate high immigration rates since high migration rates between populations can lead to differences in inbreeding estimates among loci (ROBERTSON, 1974; NEI and MARUYAMA, 1975). C. henryi at Cherry tree also had the highest genetic diversity indices $\left(H_{\mathrm{O}}\right.$, and $M N A$; Table 1). It is possible that this population receives genes from another population external to this study, or that gene flow between the two species is directional such that $C$. henryi is a more frequent recipient.

\section{Implications of population panmixia for LD mapping}

This study has indicated population panmixia between plant species that are regarded as separate taxonomic entities. Populations of $C$. henryi and C. variega$t a$ had no species-specific alleles or significant allele frequency differences at each of two sympatric locations. However, site-specific alleles were observed between the geographic sites. The two sites, Cherry tree and Bunyaville, are separated by the Border Ranges. Several considerations for $L D$ mapping, conservation, plantation forestry and breeding, can be made based on the present data. First, the present data suggest that the two taxa form a panmictic unit at the two sites studied, where population structure is principally determined by geographic isolation. One implication of this for $L D$ mapping is that there is little need for concern about cryptic hybridisation when sampling from sites of sympatry. Although it may be prudent to still manage samples as two species separately, inadvertent sampling of the alternate species or sampling of individuals of intermediate morphology should not significantly contribute to false conclusions when conducting $L D$ mapping. Second, correction for geographic isolation may be a greater consideration for association tests in both taxa. The data in this study suggest structuring over the sampled range was quite weak. However, an expansion of this study to include more sites will be necessary to confirm whether this is a range wide feature. A large study is currently underway to determine if these results can be replicated in a range-wide context, and to investigate signatures of selection at the quantitative traits that distinguish these species. Also, the use of slowly evolving loci and candidate genes will be useful in the future to provide a more general conclusion about population structure for 
$L D$ mapping. In conclusion, differentiation between the two species of spotted gum was less than that due to geographic isolation indicating they are a single gene pool, with little if any intrinsic reproductive isolation between the species. The lack of known barriers for hybridisation yet a dearth of evidence for morphological hybrids suggest that these two "species" might be best viewed as a single evolutionary lineage that encompasses some morphological segregates that are used to define taxonomic groups.

\section{Acknowledgement}

We thank Mr. Mike Henson (Forestry New South Wales) for funding field sample collections in New South Wales, Queensland Environment Protection Agency (EPA) for logistical support, Mr. DAVID KLEINIG of Dendro Seeds for technical help during sample collections, and Mr. TONY BEAN of the Queensland Herbarium for help with sample identification. This work forms part of J.W. Ochieng's Doctoral Research, supported by a Commonwealth Scholarship, Australian Research Council (ARC) Linkage Grant, Department of Primary Industries and Fisheries, and Forestry Plantations Queensland.

\section{Literature Cited}

BeAumont, M. A (2005): Adaptation and speciation: what can $F_{\mathrm{ST}}$ tell us? Trends in Ecology and Evolution 20: 435-440.

CAVAlli-Sforza, L. L. (1966): Population structure and human evolution. Proceedings of the Royal Society of London B 164: 362-379.

CAvalli-Sforza, L. L. and W. F. Edwards (1967): Phylogenetic analysis: models and estimation procedures. Evolution 32: 550-570.

Dickinson, G. R., D. J. Lee and J. R. Huth (2004): Early plantation growth and tolerance to Ramularia Shoot Blight of provenances of the spotted gums taxa on a range of sites in southern Queensland. Australian Forestry 67: 122-130.

Doebley, J. and L. LuKens (1998): Transcriptional regulators and the evolution of plant form. The Plant Cell 10: 1075-1082.

Doebley, J. and A. Stec (1991): Genetic analysis of the morphological differences between maize and teosinte. Genetics 129: 285-295.

Excoffier, L., P. E. Smouse and J. M. Quattro (1992): Analysis of molecular variance inferred from metric distances among DNA haplotypes - application to human mitochondrial - DNA restriction data. Genetics 131: $479-491$.

Felsenstein, J. (1995): PHYLIP: phylogeny inference package. University of Washington, Seattle.

Goudet, J., M. Raymond, T. Demeeus and F. Rousset (1996): Testing differentiation in diploid populations. Genetics 144: 1933-1940.

Grahame, J. W., C. S. Wilding and R. K. Butlin (2006): Adaptation to a steep environmental gradient and an associated barrier to gene exchange in Littorina saxatilis. Evolution 60: 268-278.

HARTL, D. L. (2000): A primer of population genetics. Sinauer Associates Inc., Sunderland.

HiLl, K. D. and L. A. S. Johnson (1995): Systematic studies in the eucalypts 7. A revision of the bloodwoods, genus Corymbia (Myrtaceae). Telopea 6: 185-504.
HirschHorn, J. N., K. LOHMueller, E. Byrne and K. HiRsCHHORN (2002): A comprehensive review of genetic association studies. Genetics in Medicine 4: 45-61.

Jones, M. E., R. L. Stokoe, M. J. Cross, L. J. Scott, T. L. MAGUIRE and M. SHEPHERD (2001): Isolation of microsatellite loci from spotted gum (Corymbia variegata), and cross-species amplification in Corymbia and Eucalyptus. Molecular ecology notes 1: 276-278.

KING, R. (2004): Spatial structure and population genetic variation in a Eucalypt species complex $\mathrm{PhD}$ thesis, Griffith University, Australia.

LEE, D. J. (2007): Development of Corymbia species and hybrids for plantations in eastern Australia. Australian Forestry 70: 11-17.

LeE, D., J. Brawner and P. Pomroy (2004): Genetic variation in early growth and disease tolerance of Corymbia citriodora subsp. variegata in Southern Queensland, Australia. In: International IUFRO Conference on Silviculture and Improvement of Eucalypts, BoRRALHO, N. M. G., Pereira, J. S., Marques, C., Coutinho, J., Madeira, M. and Tome, M. (eds.), pp. 185-186. Aveiro, Portugal.

Lexer, C., A. Kremer and R. J. Petit (2006): Shared alleles in sympatric oaks: recurrent gene flow is a more parsimonious explanation than ancestral polymorphim. Molecular Ecology 15: 2007-2012.

Lexer, C., C. A. Buerkle, J. A. Joseph, B. Heinze and M. F. FAY (2007): Admixture in European populus hybrid zones makes feasible the mapping of loci that contribute to reproductive isolation and trait differences. Heredity 98: 74-84.

LEWONTIN, R. C. and J. KRAKAUER (1973): Distribution of gene frequency as a test of the theory of the selective neutrality of polymorphisms. Genetics 74: 175-195.

McDonald, M. W., P. A. Butcher, C. J. Bell and J. S. LARMOUR (2000): Intra- and interspecific allozyme variation in eucalypts from the spotted gum group, Corymbia, section 'Politaria' (Myrtaceae). Australian Systematic Botany 13: 491-507.

Muir, G. and C. SchlotTERER (2005): Evidence for shared ancestral polymorphism rather than recurrent gene flow at microsatellite loci differentiating two hybridizing oaks (Quercus spp.). Molecular Ecology 14: 549-561.

MUIR, G. and C. SChLOTTERER (2006): Moving beyond single-locus studies to characterize hybridization between oaks (Quercus ssp.). Molecular Ecology 15: 2301-2304.

NEI, M. (1987): Molecular evolutionary genetics. Columbia University Press, New York.

NeI, M. and T. MARUYAMA (1975): Lewontin-Krakauer test for neutral genes. Genetics 80: 395-395.

Ochieng, J. W., P. R. Baverstock, R. J. Henry and M. SHEPHERD (2006): Population panmixia in a spotted gum species complex (Mytaceae): Implications for association mapping. Plant and Animal Genomes Conference XIV PAG, San Diego, USA: P657.

Ochieng, J. W., R. J. Henry, P. R. Baverstock, D. A. StEANE and M. SHEPHERD (2007): Nuclear Ribosomal Pseudogenes resolve a corroborated Monophyly of the eucalypt genus Corymbia despite misleading hypotheses at functional ITS paralogs. Molecular Phylogenetics and Evolution 44: 752-764.

Ochieng, J. W., D. A. Steane, P. Y. Ladiges, P. R. BaverSTOCK, R. J. HENRY and M. SHEPHERD (2007): Microsatellites retain phylogenetic signals across genera in eucalypts (Myrtaceae). Genetics and Molecular Biology, in press. 
ORR, A. H (2001): The genetics of species differences. Trends in Ecology and Evolution 16: 343-349.

PANova, M., J. Hollander and K. JohanNESSON (2006): Site-specific genetic divergence in parallel hybrid zones suggests nonallopatric evolution of reproductive barriers. Molecular Ecology doi: 10.1111/j.1365-294X.2006. 03067.x.

Pritchard, J. K. and N. A. Rosenberg (1999): Use of Unlinked Genetic Markers to Detect Population Stratification in Association Studies. American Journal of Human Genetics 65: 220-228.

PRITChARD, J. K. and M. PRZEWORSKI (2001): Linkage disequilibrium in humans: models and data. American Journal of Human Genetics 69: 1-14.

RAYMOND, M. and F. RousseT (1995): An exact test for population differentiation. Evolution 49: 1280-1283.

RICE, W. R. (1989): Analyzing tables of statistical tests. Evolution 43: 223-225.

ROBERTSON, A. (1975): Remarks on the LewontinKrakauer test. Genetics 80: 396-396.

Schneider, D., D. Roessli and L. Excoffier (2000): ARLEQUIN, pp. A software for population genetics data analysis. Genetics and Biometry Laboratory, University of Geneva, Geneva.
Shepherd, M., S. Kasem, D. Lee and R. Henry (2006): Construction of microsatellite genetic linkage maps for Corymbia. Silvae Genetica 55: 228-238.

SLATKIN, M. (1995): A measure of population subdivision based on microsatellite allele frequencies. Genetics 139: 457-462.

Southerton, S. G., P. BirT and H. A. Ford (2004): Review of gene movement by bats and birds and its potential significance for eucalypt plantation forestry. Australian Forestry. 67: 44-53.

Thamarus, K. A., K. Groom, J. Murrel, M. Byrne and G. F. Moran (2002): A genetic linkage map for Eucalyptus globulus with candidate loci for wood, fibre, and floral traits. Theoretical and Applied Genetics 104: 379-387.

WeIR, B. S. and C. C. Cockerham (1984): Estimating F-Statistics for the Analysis of Population Structure. Evolution 38: 1358-1370.

WRIGHT, S. (1969): Evolution and genetics of populations II. The theory of gene frequencies. University of Chicago press.

Wu, C. I. (2001): The genic view of the process of speciation. Journal of Evolutionary Biology 14: 851-865.

\title{
Pollen Dispersal and Its Spatial Distribution in a Seed Orchard of Larix kaempferi (Lamb.) Carr.
}

\author{
By Zhang Zhuowen*), Sui Juanjuan, Mei Li and Shu Changqing
}

Faculty of Horticulture and Forestry Science, Huazhong Agricultural University, Wuhan 430070, P. R. China

(Received $4^{\text {th }}$ May 2007)

\begin{abstract}
Pollen dispersal and its spatial distribution in a seed orchard of Larix kaempferi in Changlinggang, Jianshi, Hubei Province has been studied for 3 years. The results show that pollen dispersal is directly affected by weather conditions, with wind speed being the main factor controlling pollen dispersal. Pollen dispersal follows a date rhythm of low-high-low during the whole pollen dispersal season with a peak date for 3-5 days, and a time rhythm of low-high-low with the peak time at 10:00-16:00 during the day. For pollen density in the air there are significant differences among dates, and among different day times during dispersing. There are no significant differences between pollen densities in space with regard to horizontal directions, 8 orientations, and different positions in the tree crown in this seed orchard, in all of these cases pollens are evenly distributed. There are significant differences for pollen densities among different vertical heights, showing a cluster distribution type. The pollination level in this seed orchard is very low and needs a supplement mass pollination (SMP).
\end{abstract}

*) E-Mail: zzhwzhang@@mail.hzau.edu.cn
Key words: Larix kaempferi (Lamb.) Carr, seed orchard, pollen dispersal, spatial distribution, pollination level.

\section{Introduction}

Larix kaempferi is a deciduous tree belonging to the genus Larix, family Pinaceae. It grows very fast with the characteristic of being tolerant to water logged soils, and its timber is widely used for its high quality. Both male cones and female cones grow on the same mature tree. The seed yield per Larix kaempferi mother tree is very low. Based on the data of the grafted Larix kaempferi clonal seed orchard located at Dagujia, Liaoning Province, Wang YoucAi et al. (WANG YoucAi et al., 2000) found that the seed yield was $2110 \mathrm{~kg} \cdot \mathrm{a}^{-1} \cdot \mathrm{hm}^{-2}$, $25100 \mathrm{~kg} \cdot \mathrm{a}^{-1} \cdot \mathrm{hm}^{-2}$ and $16143 \mathrm{~kg} \cdot \mathrm{a}^{-1} \cdot \mathrm{hm}^{-2}$ for trees younger than 16 years, between 22 to 26 years old, and between 27 to 31 years old, respectively. A seed-bearing periodicity phenomenon of bumper year - off year is very common in a seed orchard. The seed production is not enough for local afforestation at the moment. This situation may be related to pollination in the seed orchard, Wu DeJun et al. (Wu DEJUn et al., 1997) found 